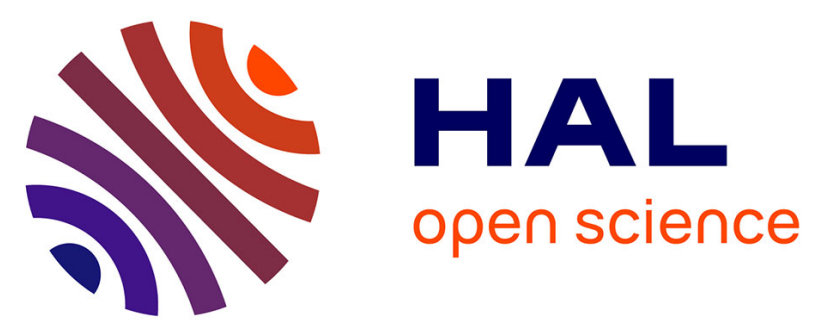

\title{
Comparison of synthetic medium and wastewater used as dilution medium to design scalable microbial anodes: Application to food waste treatment
}

Elise Blanchet, Elie Desmond-Le Quemener, Benjamin Erable, Arnaud Bridier, Théodore Bouchez, Alain Bergel

\section{To cite this version:}

Elise Blanchet, Elie Desmond-Le Quemener, Benjamin Erable, Arnaud Bridier, Théodore Bouchez, et al.. Comparison of synthetic medium and wastewater used as dilution medium to design scalable microbial anodes: Application to food waste treatment. Bioresource Technology, 2015, vol. 185, pp. 106-115. 10.1016/j.biortech.2015.02.097 . hal-01149751

\author{
HAL Id: hal-01149751 \\ https://hal.science/hal-01149751
}

Submitted on 7 May 2015

HAL is a multi-disciplinary open access archive for the deposit and dissemination of scientific research documents, whether they are published or not. The documents may come from teaching and research institutions in France or abroad, or from public or private research centers.
L'archive ouverte pluridisciplinaire HAL, est destinée au dépôt et à la diffusion de documents scientifiques de niveau recherche, publiés ou non, émanant des établissements d'enseignement et de recherche français ou étrangers, des laboratoires publics ou privés. 


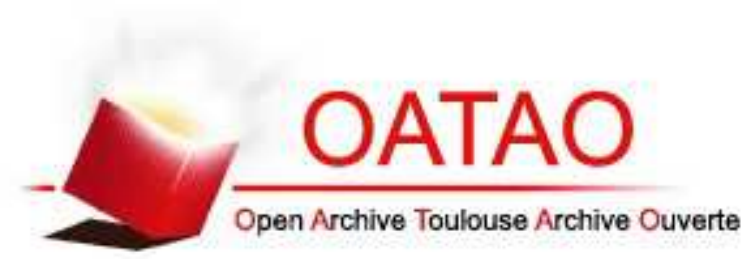

\section{Open Archive TOULOUSE Archive Ouverte (OATAO)}

OATAO is an open access repository that collects the work of Toulouse researchers and makes it freely available over the web where possible.

This is an author-deposited version published in : http://oatao.univ-toulouse.fr/ Eprints ID : 13879

To link to this article : DOI:10.1016/j.biortech.2015.02.097

URL : http://dx.doi.org/10.1016/j.biortech.2015.02.097

\section{To cite this version :}

Blanchet, Elise and Desmond-Le Quemener, Elie and Erable, Benjamin and Bridier, Arnaud and Bouchez, Théodore and Bergel, Alain Comparison of synthetic medium and wastewater used as dilution medium to design scalable microbial anodes: Application to food waste treatment. (2015) Bioresource Technology, vol. 185. pp. 106-115. ISSN 0960-8524

Any correspondance concerning this service should be sent to the repository administrator: staff-oatao@ listes-diff.inp-toulouse.fr 


\title{
Comparison of synthetic medium and wastewater used as dilution medium to design scalable microbial anodes: Application to food waste treatment
}

\author{
Elise Blanchet ${ }^{\mathrm{a}, *}$, Elie Desmond ${ }^{\mathrm{b}}$, Benjamin Erable ${ }^{\mathrm{a}}$, Arnaud Bridier ${ }^{\mathrm{b}}$, Théodore Bouchez ${ }^{\mathrm{b}}$, Alain Bergel ${ }^{\mathrm{a}}$ \\ a Laboratoire de Génie Chimique (LGC), CNRS, Université de Toulouse (INPT), 4 allée Emile Monso, BP 84234, 31432 Toulouse, France \\ ${ }^{\mathrm{b}}$ Irstea, UR HBAN, 1 rue Pierre-Gilles de Gennes, 92761 Antony cedex, France
}

H I G H L I G H T S

Bioanodes were designed by replacing synthetic medium by costless wastewater.

Using wastewater ensured $50 \%$ of the current density obtained in synthetic medium.

Bioanodes differed in biofilm structures and redox charge contents.

Current densities were directly correlated to the enrichment in Geobacteraceae.

Wastewater is a suitable medium to design bioanodes for food waste treatment.

Keywords:

Bioanode

Bioelectrochemical system

Geobacteraceae

Wastewater

Food waste

\begin{abstract}
A B S T R A C T
The objective was to replace synthetic medium by wastewater as a strategy to design low-cost scalable bioanodes. The addition of activated sludge was necessary to form primary bioanodes that were then used as the inoculum to form the secondary bioanodes. Bioanodes formed in synthetic medium with acetate $10 \mathrm{mM}$ provided current densities of $21.9 \pm 2.1 \mathrm{~A} / \mathrm{m}^{2}$, while bioanodes formed in wastewater gave $10.3 \pm 0.1 \mathrm{~A} / \mathrm{m}^{2}$. The difference was explained in terms of biofilm structure, electrochemical kinetics and redox charge content of the biofilms. In both media, current densities were straightforwardly correlated with the biofilm enrichment in Geobacteraceae but, inside this family, Geobacter sulfurreducens and an uncultured Geobacter sp. were dominant in the synthetic medium, while growth of another Geobacter $\mathrm{sp}$. was favoured in wastewater. Finally, the primary/secondary procedure succeeded in designing bioanodes to treat food wastes by using wastewater as dilution medium, with current densities of $7 \pm 1.1 \mathrm{~A} / \mathrm{m}$
\end{abstract}

\section{Introduction}

The treatment of the domestic and industrial wastes that are produced by developed countries consumes huge amounts of energy. Abating the organic matter to a level that permits its disposal in natural environments generally involves aerobic processes, which consume considerable amounts of electrical energy for aeration (Miksch et al., 2013). Nowadays, much research focuses on extracting the chemical energy contained in so much wasted organic matter in order to treat it and, even better, to generate a positive energy balance. Microbial electrochemical technologies (METs) may be the tools that will make this dream a reality (Wang and Ren, 2013). They would offer the great advantages of abating

\footnotetext{
* Corresponding author. Tel.: +33 534323626.

E-mail address: blanchet.elise@gmail.com (E. Blanchet).
}

organic matter in anaerobic conditions, thus saving the cost of aeration, and converting the chemical energy of organic compounds directly into electrical energy (microbial fuel cells), hydrogen (microbial electrolysis cells) or other services (microbial desalination cells, for example).

All these applications are based on the implementation of microbial bioanodes that use electrochemically active microorganisms able to oxidize the organic compounds and to transfer the electrons produced to the electrode material. Lab studies have had considerable successes in bioanode design by working in well-controlled conditions, in synthetic medium and with acetate as substrate (Rimboud et al., 2014). Current densities of $5 \mathrm{~A} / \mathrm{m}^{2}$ have been obtained on graphite electrodes (Liu et al., 2008) and even more with sophisticated electrode designs, e.g. $80 \mathrm{~A} / \mathrm{m}^{2}$ with stainless steel foam (Ketep et al., 2014) and up to $67 \mathrm{~A} / \mathrm{m}^{2}$ with layered corrugated carbon (Baudler et al., 2014). 
A few bioanodes have also been successfully designed to treat real raw effluents (Pant et al., 2010) but current densities remain modest, for example $0.18 \mathrm{~A} / \mathrm{m}^{2}$ has been reported with urban wastewater (Rodrigo et al., 2007), $2 \mathrm{~A} / \mathrm{m}^{2}$ with brewery wastewater (Feng et al., 2008), $3 \mathrm{~A} / \mathrm{m}^{2}$ with chocolate industry wastewater (Patil et al., 2009), and 4-6 A/ $\mathrm{m}^{2}$ with paper mill effluent (Ketep et al., 2013). So far, the gap is large between the performance reached in synthetic media and that obtained in raw effluents.

Designing METs for the treatment of food wastes should be of great economic interest because food wastes are generated abundantly in concentrated form and need to be treated before disposal (Pant et al., 2013). In 2010, more than 34 million tons of food waste was generated in the United States, of which less than $3 \%$ was recovered and recycled, according to the U.S. Environmental Protection Agency (Li et al., 2013). Despite the high economic interest, studies that have investigated bioanodes able to treat food wastes remain rare (Table 1 ).

Food wastes are generally high in soluble COD and consequently need to be diluted to be oxidized by bioanodes. For this purpose, synthetic medium, drinking water or deionized water has generally been used. To our knowledge, only one study (Tenca et al., 2013) has overcome the problem by using food processing water with a fairly low COD $(1.8 \mathrm{~g} / \mathrm{L})$ that did not require dilution. If the objective is to treat large quantities of wastes, it will not be possible to scale up large-sized METs that require huge amounts of phosphate or other buffer salts and the addition of micro-nutriments and vitamins. The cost would be too high, the release of salt would induce serious new environmental problems or require costly downstream separation and re-cycling processes. Using tap water would be less costly, but unfortunate in a world that should be increasing its efforts to preserve drinking water. Pant et al. (2013) have proposed a clever solution to this critical issue by using domestic wastewater as a dilution medium. The current densities obtained were modest $\left(65 \mathrm{~mA} / \mathrm{m}^{2}\right)$ but the idea is surely interesting enough to deserve further investigation. Actually, if efficient bioanodes could be formed by diluting food wastes, or any other concentrated wastes, in wastewater, it would open up a cost-free method that could be easily scaled-up to large sized industrial METs.

The purpose of the present work was to help to define a scalable strategy for bioanode design by assessing the suitability of wastewater as a dilution medium. The work was based on the comparison of bioanodes designed in identical conditions in wastewater and in a synthetic medium. Bioanodes were formed in an optimal synthetic solution composed of phosphate buffer, macro-nutriments, trace minerals and vitamins, as commonly used in MET studies. In parallel, the same procedure was implemented in wastewater without any supplementation. The synthetic medium was inoculated with activated sludge and the necessity for the same inoculation with wastewater was discussed. In both cases, the bioanodes were formed in electroanalytical conditions under constant applied potential. The well-controlled electroanalytical conditions allowed the bioanode itself to be characterized by minimizing the interactions and rate-limiting steps that can occur in microbial fuel cells and microbial electrolysis cells (Rimboud et al., 2014). The design procedure consisted of, firstly, forming a primary bioanode that was then used to inoculate a secondary bioanode. This procedure has already been described in the literature and has led to secondary bioanodes displaying twice the current of the primary ones (Liu et al., 2008) and sustaining their performance over long periods (Baudler et al., 2014). This strategy designed in lab conditions with synthetic medium should be of great interest for real effluent because of its effectiveness and its capacity to be reproduced at large scale.

The bioanodes formed in synthetic medium and wastewater were compared by crossing electrochemical measurements, microscopy imaging and analysis of the microbial communities by $16 \mathrm{~S}$ rRNA pyrosequencing. The comparison was performed with acetate as the substrate and the practical interest of the procedure was then checked with food wastes.

\section{Methods}

\subsection{Electrochemical setup}

Sealed vessels $(600 \mathrm{~mL})$ served as electrochemical cells that hosted the microbial medium and 3 electrodes. The 3-electrode set-ups consisted of a carbon cloth working electrode of $2 * 3 \mathrm{~cm}^{2}$ geometric surface area (Paxitech, Grenoble, France), a saturated calomel reference electrode (SCE, Radiometer Analytical, $+0.24 \mathrm{~V}$ vs. SHE) and a $2 * 3 \mathrm{~cm}^{2}$ platinum grid used as the auxiliary electrode. The anode and cathode were connected to the electrical circuit by a 12 -cm-long, 1 -mm-diameter platinum wire. The anode (working electrode) was located at around $10 \mathrm{~cm}$ from the auxiliary electrode and as close as possible (around $0.5 \mathrm{~cm}$ ) to the reference electrode. The working electrode was polarized at $0.15 \mathrm{~V}$ vs. SCE using a VSP potentiostat (Bio-Logic SA) interfacing with a computer (software EC-Lab) and the current was recorded every $10 \mathrm{~min}$. Chronoamperometry was sometimes interrupted to perform cyclic voltammetry at low scan rate $(1 \mathrm{mV} / \mathrm{s})$ in the -0.6 to $+0.3 \mathrm{~V}$ vs. SCE range.

The reactors were maintained at $27^{\circ} \mathrm{C} \pm 2{ }^{\circ} \mathrm{C}$ in a water bath and were initially purged with nitrogen for $15 \mathrm{~min}$ to remove oxygen. Substrate solutions in reactors were continuously lightly stirred $(100 \mathrm{rpm})$.

Table 1

Studies using food wastes as a substrate to power microbial fuel cells or microbial electrolysis cells.

\begin{tabular}{|c|c|c|c|c|c|c|c|}
\hline Food waste type & $\begin{array}{l}\mathrm{sCOD} \\
\left(\mathrm{gO}_{2} / \mathrm{L}\right) \\
\end{array}$ & $\begin{array}{l}\text { Dilution } \\
\text { medium }\end{array}$ & Inoculum & Bioanode type & Configuration & $\begin{array}{l}\text { Performances } \\
\left(\mathrm{A} / \mathrm{m}^{2}\right)\end{array}$ & References \\
\hline $\begin{array}{l}\text { Food processing wastewater } \\
\quad \text { (Cereal) }\end{array}$ & 8.9 & $\begin{array}{l}\text { Synthetic } \\
\text { medium }\end{array}$ & Sludge & $\begin{array}{l}\text { Toray carbon paper } \\
\left(22.5 \mathrm{~cm}^{2}\right)\end{array}$ & MFC & 0.24 & Oh and Logan (2005) \\
\hline $\begin{array}{l}\text { Food industry waste } \\
\text { (Yoghurt waste) }\end{array}$ & $\mathrm{N} / \mathrm{A}$ & $\begin{array}{l}\text { Synthetic } \\
\text { medium }\end{array}$ & $\begin{array}{l}\text { Anaerobic } \\
\text { sludge }\end{array}$ & Graphite felt $\left(10 \mathrm{~cm}^{2}\right)$ & MFC & 0.4 & $\begin{array}{l}\text { Cercado-Quezada et al. } \\
\text { (2010) }\end{array}$ \\
\hline Canteen food waste & 12 & Tap water & $\begin{array}{l}\text { Anaerobic } \\
\text { sludge }\end{array}$ & Graphite plate $\left(70 \mathrm{~cm}^{2}\right)$ & MFC & 1.6 & Goud et al. (2011) \\
\hline $\begin{array}{l}\text { Food waste from student's } \\
\text { cafeteria }\end{array}$ & 27.5 & $\begin{array}{l}\text { Synthetic } \\
\text { medium }\end{array}$ & $\begin{array}{l}\text { Anaerobic } \\
\text { sludge }\end{array}$ & Carbon felt $\left(50 \mathrm{~cm}^{2}\right)$ & MFC & 0.45 & Choi et al. (2011) \\
\hline Food waste leachate & 12.7 & Deionized water & $\begin{array}{l}\text { Anaerobic } \\
\text { sludge }\end{array}$ & Carbon felt $\left(21 \mathrm{~cm}^{2}\right)$ & MFC & 0.1 & Li et al. (2013) \\
\hline $\begin{array}{l}\text { Fermented reconstituted } \\
\text { food waste }\end{array}$ & 13 & $\begin{array}{l}\text { Domestic } \\
\text { wastewater }\end{array}$ & Compost & Carbon felt $\left(10 \mathrm{~cm}^{2}\right)$ & MFC & 0.065 & Pant et al. (2013) \\
\hline Food processing wastewater & 1.8 & No dilution & $\begin{array}{l}\text { Acclimated } \\
\text { biomass }\end{array}$ & Graphite fiber brushes & MEC & 2 & Tenca et al. (2013) \\
\hline
\end{tabular}




\subsection{Synthetic medium, activated sludge, wastewater and food wastes}

The synthetic medium contained (Liu et al., 2008): $\mathrm{NaH}_{2} \mathrm{PO}_{4} \cdot \mathrm{H}_{2} \mathrm{O}$ (2.69 g/L), $\mathrm{Na}_{2} \mathrm{HPO}_{4}(4.33 \mathrm{~g} / \mathrm{L}), \mathrm{KCl}(0.13 \mathrm{~g} / \mathrm{L})$ and $10 \mathrm{~mL} / \mathrm{L}$ macronutrients $\left(\mathrm{NH}_{4} \mathrm{Cl} 31 \mathrm{~g} / \mathrm{L} ; \mathrm{MgSO}_{4} \cdot 7 \mathrm{H}_{2} \mathrm{O} 10 \mathrm{~g} / \mathrm{L} ; \mathrm{CaCl}_{2} 0.57 \mathrm{~g} / \mathrm{L}\right)$. pH was adjusted to 7.0 and the solution was sterilized in an autoclave $\left(121^{\circ} \mathrm{C}\right.$ for $\left.20 \mathrm{~min}\right)$. Trace mineral mix $(10 \mathrm{~mL} / \mathrm{L}$, ATCC MD-TMS and vitamin mix (10 mL/L, ATCC MD-VS) were added by filtration. Acetate $(10 \mathrm{mM})$ was finally added as the substrate. Before inoculation, the medium was purged with nitrogen for $15 \mathrm{~min}$. Acetate concentration was monitored by an enzymatic kit (K-ACETAK, Megazyme).

Activated sludge sampled in a wastewater treatment plant (Castanet-Tolosan, France) was used as the inoculum (3.3\% v/v) for the primary bioanode design. The chemical oxygen demand of the activated sludge was $4100 \mathrm{mgO}_{2} / \mathrm{L}$.

Wastewater was collected from the same wastewater treatment plant (Castanet-Tolosan, France). The average soluble COD was about $390 \mathrm{mg} / \mathrm{L}$, ammonium $48 \mathrm{mg} / \mathrm{L}$, nitrate concentration less than $0.5 \mathrm{mg} / \mathrm{L}$ and sulfate $27 \mathrm{mg} / \mathrm{L}$. The average $\mathrm{pH}$ was 7.8 .

Food wastes were prepared with common food components in a reproducible way to mimic the mean composition of food wastes from supermarkets and water was added to obtain a waste with $10 \%$ dry mass. The raw components were defrosted $24 \mathrm{~h}$ before weighing. One kilogram of reconstituted biowaste was prepared with $81 \mathrm{~g}$ of potatoes, $34 \mathrm{~g}$ of tomatoes, $81 \mathrm{~g}$ of minced meat, $7 \mathrm{~g}$ of biscuit and $42 \mathrm{~g}$ of milk powder. $756 \mathrm{~mL}$ of water was added and the components were ground and mixed together. This mixture was stored 5 days at $30^{\circ} \mathrm{C}$ in $1 \mathrm{~L}$ bottles for fermentation. During these 5 days, food waste fermented (i.e. hydrolyses and acidogenesis steps) with its indigenous flora, mostly anaerobic. The food waste was then centrifuged and the supernatant sampled and frozen at $-20^{\circ} \mathrm{C}$. The final $\mathrm{pH}$ was 3.4 and soluble COD $42.6 \mathrm{gO}_{2} / \mathrm{L}$. The composition was analyzed using an HPLC giving ( $(\mathrm{COD} / \mathrm{L})$ : butyric acid 9.7, lactic acid 5.3, acetic acid 0.4 , others (proteins, sugars, other organic acids, lipids) 27.2.

Addition of $10 \mathrm{~mL}$ of waste into the $600 \mathrm{~mL}$ reactors corresponded to $700 \mathrm{mg} / \mathrm{L}$ COD, which was of the same order of magnitude as $10 \mathrm{mM}$ acetate in term of COD.

COD was measured using kit LCK514 kit (Hach Lange, range of measurement $100-2000 \mathrm{gO}_{2} / \mathrm{L}$ ). Volatile fatty acids composition was analyzed using an HPLC (Thermo Scientific, France) equipped with a Rezex ROA-Organic acid $\mathrm{H}+(8 \%), 250 * 4.6 \mathrm{~mm}$ phase-reverse column (Phenomenex, France) thermostated at $30^{\circ} \mathrm{C}$ and associated with a refractive Index detector in series with a UV detector. The elution was performed at $170 \mu \mathrm{L} / \mathrm{min}$ with an aqueous solution of sulphuric acid $10 \mathrm{mM}(\mathrm{pH} \mathrm{2.2)}$. Before analysis, samples were thawed, diluted 10 times in the eluent and filtered at $0.2 \mu \mathrm{m}$. The column was calibrated with a mixture of methanoate, acetate, lactate, propionate and butyrate, in the analysis concentration range.

\subsection{Bioanode formation}

Experiments were systematically carried out in duplicate. A total of 8 reactors were implemented to study 4 different conditions: synthetic medium with $10 \mathrm{mM}$ acetate inoculated with fresh activated sludge in reactors R1 and R2; wastewater with $10 \mathrm{mM}$ acetate inoculated with fresh activated sludge in R3 and R4; wastewater with $10 \mathrm{mM}$ acetate without inoculum in R5 and R6; wastewater with reconstituted food waste inoculated with fresh activated sludge in R7 and R8.

The primary bioanodes were formed with 4 consecutive batches. Each batch corresponded to the replacement of the reactor solution with fresh solution. After 4 batches, a clean working electrode (same surface area as the primary) was immersed in each reactor.
The electrodes were connected together and consequently polarized at the same potential ( $0.15 \mathrm{~V}$ vs. SCE). From this step onwards, activated sludge was no longer present in the solutions. The secondary bioanode was developed under semi-batch conditions, with either full replacement of the reactor solution or a simple substrate pulse into the reactors. The last phase of the procedure was to remove the primary bioanode and characterize the secondary bioanode alone. At the end of the experiments, the bioanodes were cut into 3 portions to be imaged by scanning electron microscopy, epifluorescent microscopy and for 16S rRNA pyrosequencing.

\subsection{Microscopic imaging}

\subsubsection{Scanning electron microscopy (SEM)}

Bioanodes were fixed in phosphate buffer $(400 \mathrm{mM}, \mathrm{pH}=7.4)$ with $4 \%$ glutaraldehyde. They were rinsed in phosphate buffer containing saccharose $(0.4 \mathrm{M})$ and dehydrated by immersion in increasing concentrations of acetone $(50 \%, 70 \%, 100 \%)$, then in acetone and hexamethyldisilazane (50:50), and in 100\% hexamethyldisilazane (HMDS). The last batch of HMDS was dried until complete evaporation. The bioanodes were observed with a LEO 435 VP scanning electron microscope.

\subsubsection{Epifluorescence microscopy}

Biofilms were stained with acridine orange 0.01\% (A6014 Sigma) for $10 \mathrm{~min}$, then carefully washed with distilled water and dried at ambient temperature. The samples were imaged with a Carl Zeiss Axiomalger M2 microscope equipped for epifluorescence with an $\mathrm{HBO} 50 \mathrm{~W}$ ac mercury light source and the Zeidd 09 filter (excitor HP450-490, reflector FT 10, Barrier filter LP520). Images were acquired with a monochrome digital camera (evolution VF) every $0.5 \mu \mathrm{m}$ along the $Z$-axis and the set of images was processed with the Axiovision ${ }^{\circledR}$ software.

Epifluorescence images were analyzed by grey scale interpretation to calculate the proportion of the electrode surface covered by the biofilm. The grey intensity threshold between the areas covered by the biofilm and the non-covered areas was set manually. Grey levels greater than the threshold value were considered as biofilm-covered areas, while grey levels lower than the threshold were considered as clean areas.

\subsection{Microbial community analysis}

Samples of $2 \mathrm{~mL}$ were taken from the wastewater and from the activated sludge. Primary bioanodes were collected from R1, R3 and $\mathrm{R} 5$ at the end of step 2 (Fig. 1) and secondary bioanodes at the end of the experiments. The biofilms were collected by sonication in $2 \mathrm{~mL}$ of distilled water ( $3 \mathrm{~min}$ at $80 \mathrm{~W}$ ). Cells were concentrated by centrifugation and re-suspended in $500 \mu \mathrm{L}$ of water. The DNA was extracted from $250 \mu \mathrm{L}$ of each sample using the MOBIO PowerSoil $^{\circledR}$ DNA Isolation kit according to the manufacturer's instructions.

DNA concentrations were checked with absorbance at $260 \mathrm{~nm}$. Sequencing of V3-V4 regions from ribosomal genes was then performed on the GeT-PlaGe platform in Toulouse using Illumina Miseq technology. The resulting data were analyzed with the open source software package QIIME "Quantitative Insights Into Microbial Ecology” (Caporaso et al., 2010b). 16S DNA sequence quality was checked using a sliding window $50 \mathrm{nt}$ long and require an average quality above 35 . The sequences were thus trimmed to the end of the last window with the required average quality and discarded if their final length was less than $250 \mathrm{nt}$. In addition, remaining reads where the longest homopolymer was more than $6 \mathrm{nt}$ long or containing an ambiguous base were also discarded. Sequences were then aligned with PyNAST (Caporaso et al., 2010a) using the Silva 108 database core-aligned set formatted 


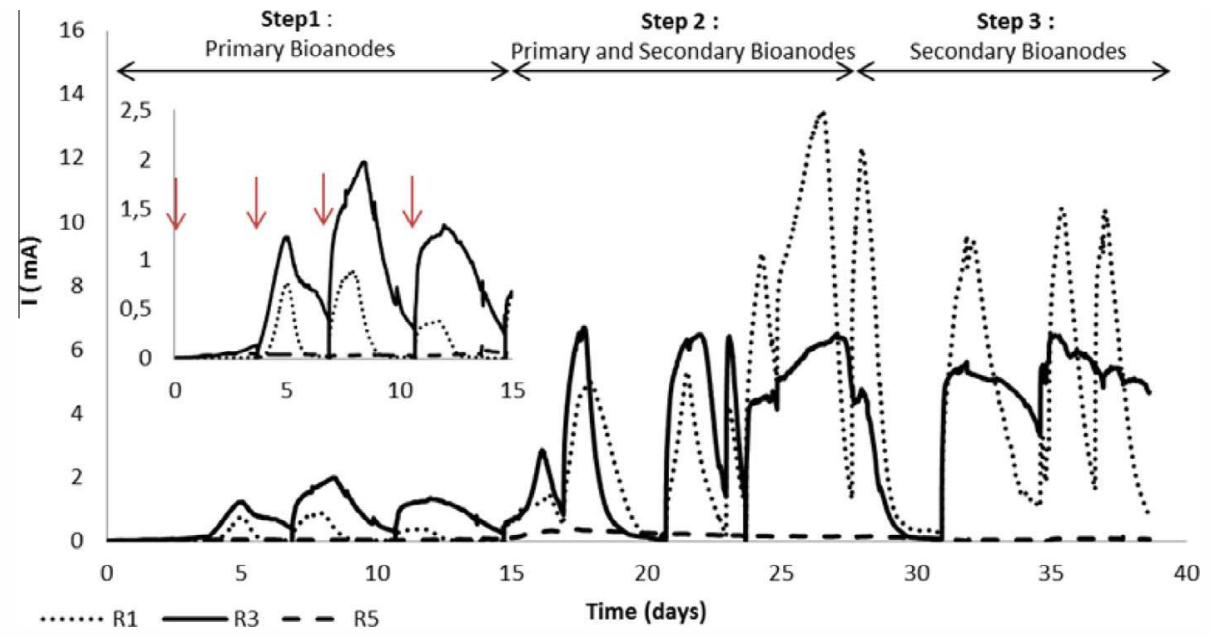

Fig. 1. Current intensities ( $\mathrm{mA}$ ) during bioanode formation in 3 different solutions: Synthetic medium - R1; Wastewater effluent - R3 and R5. Activated sludge (3.3\% v/v) was added as an inoculum in R1 and R3 but not R5. Each solution contained $10 \mathrm{mM}$ acetate. Electrodes were polarized at $0.15 \mathrm{~V}$ vs. SCE. The arrows in the inset indicate replacement of the solution by the same fresh solution.

for QIIME as a template (Quast et al., 2013). Putative chimeric sequences were identified with ChimeraSlayer and removed from the dataset (Haas et al., 2011). Remaining sequences were clustered in Operational Taxonomic Units (OTUs) at 97\% sequence similarity using uclust (Edgar, 2010). OTU taxonomic assignment was then performed with the RDP classifier (Cole et al., 2009), a 0.8 bootstrap cut-off using the longest sequence in each OTU as the representative sequence. Finally OTUs identified as Archaea or Eukarya were discarded.

For phylogenetic analysis, the 3 major OTUs belonging to Desulfuromonadales where introduced into the ARB software to check the quality of alignments and of the taxonomic assignation (Ludwig et al., 2004). Sequences of representative species of the current known diversity of the order Desulfuromonadales together with sequences of uncultured bacteria close to our sequences were then exported for deeper phylogenetic analysis. Exported sequences were aligned with PyNAST as stated above. Unambiguously aligned positions were extracted from the alignment using the BMGE program with block size of one and allowing $40 \%$ gaps in columns (Criscuolo and Gribaldo, 2010). The maximum likelihood tree was then inferred with PhyML using the GTR model with optimized equilibrium frequencies, a gamma correction to take the heterogeneity of evolutionary rates across sites into account (4 discrete classes of sites, an estimated alpha parameter and an estimated proportion of invariable sites) and SPR \& NNI topology searches with 5 random starting trees (Guindon and Gascuel, 2003). The robustness of each branch was estimated by the non-parametric bootstrap procedure implemented in PHYML (100 replicates of the original data set and the same parameters). The phylogenetic tree was edited and exported using FigTree (http://tree.bio.ed.ac.uk/software/figtree/).

\section{Results and discussion}

\subsection{Bioanode formation under applied potential}

Six bioelectrochemical reactors, R1 to R6, were run in parallel following the same procedure with 3 different solutions (in duplicate):

- R1 and 2 were filled with synthetic medium and inoculated with activated sludge,

- R3 and 4 were filled with wastewater and inoculated with activated sludge,
- R5 and 6 were filled with wastewater only, without supplementary inoculum.

Each solution contained acetate $10 \mathrm{mM}$. The carbon cloth electrodes were polarized at $0.15 \mathrm{~V}$ vs. SCE. Evolutions of the current densities were reproducible for each duplicate so, for the sake of clarity, only one curve is plotted for each solution in Fig. 1.

The bioanodes were designed following a procedure organized in 3 successive steps. The first step consisted of forming the primary bioanodes with 4 consecutive batches (inset of Fig. 1). The current increased at the beginning of the second batch for reactors R1-4, which were inoculated with activated sludge. During the third batch, current densities up to $0.7 \pm 0.6$ and $3.1 \pm 0.1 \mathrm{~A} / \mathrm{m}^{2}$ were obtained for R1-2 and R3-4, respectively. In R5-6, not inoculated with sludge, the current density did not exceed $0.15 \pm 0.1 \mathrm{~A} / \mathrm{m}^{2}$. As commonly reported, the current was generated by the biofilm-catalysed acetate oxidation:

$\mathrm{CH}_{3} \mathrm{COO}^{-}+2 \mathrm{H}_{2} \mathrm{O} \rightarrow 2 \mathrm{CO}_{2}+7 \mathrm{H}^{+}+8 \mathrm{e}^{-}$

and the current decreased at the end of each batch because of acetate depletion.

The second step started when a clean electrode (secondary electrode) was introduced into each reactor and polarized at the same potential as the primary bioanode. From this time on, the solutions used for the successive batches no longer contained the activated sludge. Starting from the second step of the procedure, the primary bioanode played the role of inoculum. Current intensities increased for all the reactors due to the colonization of the secondary electrode. Finally, the primary bioanodes were removed from the reactors and, during the third step, the current was provided by the secondary bioanodes alone. The secondary bioanodes gave maximum current densities of $21.9 \pm 2.1 \mathrm{~A} / \mathrm{m}^{2}$ and $10.3 \pm 0.1 \mathrm{~A} / \mathrm{m}^{2}$ with the synthetic medium (R1-2) and the wastewater (R3-4), respectively. This means that, in synthetic medium and wastewater, the secondary bioanodes gave respectively around 30 and 3 times higher current density than their corresponding primary bioanode.

During the second and third steps of the procedure, the solutions no longer contained the activated sludge used as an inoculum to form the R1-4 primary bioanodes. The primary electrode was expected to act as selected inoculum that emitted electroactive microbial cells to colonize the clean surface of the secondary electrode. As already reported, this strategy brought a considerable improvement from the primary to the secondary bioanodes. In previous studies, a multiplication factor of 2 has been reported 
between primary and secondary bioanodes designed in synthetic medium (Baudler et al., 2014; Liu et al., 2008). Here, in synthetic medium and in similar conditions (same applied potential, same procedure), the multiplication factor was 30 . Actually, the secondary bioanodes reached pretty common performance levels and the difference with the reported studies was due to the low currents provided by the primary bioanodes. These results demonstrate the efficiency of the strategy even when starting with relatively poorly efficient primary bioanodes.

The improvement factor of 3 obtained here in wastewater also showed the interest of the strategy when implementing real effluents. Comparing reactors R1-2 and R3-4 demonstrated that wastewater could be used as a low-cost medium to replace the more efficient but costly synthetic media. Around half of the current intensity found in synthetic medium was obtained in wastewater under identical conditions.

The R5-6 reactors constituted an exception, for which the primary/secondary electrode procedure was not fully successful. In these reactors fed with wastewater without additional inoculum, the primary bioanodes did not show significant electroactivity. The secondary bioanode showed similar poor catalytic activity in R5 but the duplicate R6 led to an improvement factor of 13 (from 0.2 to $2.6 \mathrm{~A} / \mathrm{m}^{2}$ ). With a primary biofilm showing almost no electroactivity, colonization of the secondary electrode by electroactive microbial cells could not be guaranteed and led to poor reproducibility.

The R5-6 reactors showed that wastewater itself was not an efficient inoculum. This could be due to the microbial composition of the wastewater, but it is more likely to have been caused by the too low concentration of viable bacterial biomass introduced into the reactors. Foladori et al. (2010) quantified the biomasses in wastewater and in activated sludge and found that activated sludge had a 22 times higher concentration of viable cells than wastewater. It was also previously proved that activated sludge used as inoculum accelerated the start-up process and facilitated the co-enrichment of both fermentative and electrogenic bacteria at the anode (Li et al., 2013).

\subsection{Biofilm structure}

At the end of the chronoamperometry (38 days) the bioanodes were imaged by epifluorescence microscopy and scanning electron microscopy (SEM) (Supplementary Material - Fig. S1). Epifluorescence images were analyzed by grey scale interpretation to calculate the proportion of the electrode surface covered by the biofilm. Coverage ratios were evaluated as $77 \%, 92 \%$ and $39 \%$ for R1, R3 and R5, respectively. The significantly lower biofilm coverage observed on the bioanodes formed in wastewater alone (R5) corroborated their lower electrochemical performance and the hypothesis of lower colonization due to the insufficient biomass contents of wastewater. SEM confirmed the low colonization of the bioanode formed in the absence of activated sludge (R5), which did not exhibit obvious microbial colonization at the lowest magnitude. It was necessary to resort to higher magnitudes to identify colonized patches on the fibre surfaces.

Nevertheless, for R1 and R3 with activated sludge as initial inoculum, performance of the secondary bioanode $\left(19.9 \mathrm{~A} / \mathrm{m}^{2}\right.$ and $10.4 \mathrm{~A} / \mathrm{m}^{2}$, respectively) was not correlated with the biofilm coverage ratios (77\% and $92 \%$, respectively). Higher performance but lower coverage was indeed obtained in synthetic medium compared to wastewater.

The coverage ratio alone was not sufficient to explain the differences in electrochemical performance. SEM showed that the anodes from R1 and R3 were covered with a significant layer of biofilm but with marked difference in the structures. Biofilms formed in wastewater inoculated with activated sludge (R3) completely covered the electrode surface and almost masked the woven structure of the carbon cloth electrode. They had a chaotic structure whereas the biofilms formed in synthetic medium (R1) appeared less thick and were more regularly wrapped around each fibre of the carbon cloth. The latter structure was more favourable for producing high current densities, because it exposed a larger surface area of biofilm to the solution and thus enhanced mass transfers with the solution, either for feeding the microbial cells with substrate or balancing the biofilm internal $\mathrm{pH}$ by proton extraction (Torres et al., 2008).

The synthetic medium did not contain any component that could be used as electron acceptor by the cells, except possible traces of dissolved oxygen. Any alternative electron acceptor could only come from the activated sludge inoculum in R1-2. Microbial cells were forced to use the electrode as final electron acceptor and consequently formed a biofilm tightly wrapped around the electrode fibres. In contrast, wastewater, which contained around $30 \mathrm{mg} / \mathrm{L}$ of sulfates and traces of nitrates, offered dissolved electron acceptors to the cells, and a biofilm could thus develop far from the material surface in the spaces between the fibres. If this hypothesis is right, biofilms formed in inoculated wastewater can be expected to present a larger microbial diversity than those formed in inoculated synthetic medium.

In summary, the coverage ratio observed for the bioanodes formed in inoculated wastewater was higher than for those formed in synthetic medium but the electrochemical performance was lower. The more compact structure of the biofilm obtained in wastewater did not favour mass transfers with the solution and the electron transfer inside the biofilms was probably impeded by non-electroactive microbial species. SEM at higher magnitudes did not show obvious differences between R1 and R3 bioanodes. Curved rod and rod-shaped bacteria were observed in both cases, embedded in extracellular polymeric substances.

\subsection{Electrochemical characterization}

Catalytic cyclic voltammetries were recorded at the same time (day 37) with each secondary bioanode (Fig. 2). The bioanodes formed in synthetic medium (R1) revealed a current-potential sigmoid shape with zero-current potential of $-0.45 \mathrm{~V}$ vs. SCE and the maximum plateau reached at around $-0.02 \mathrm{~V}$ vs. SCE. The overpotential of $0.43 \mathrm{~V}$ required for the sigmoid to reach the maximum current was too large to strictly correspond to a NernstMichaelis law. The Nernst-Michaelis equation links the current density $\left(j, \mathrm{~A} / \mathrm{m}^{2}\right)$ provided by a bioanode to the applied potential $(E, V)$, assuming that electron transfer from the biofilm to the electrode is fast enough to ensure the Nernst equilibrium at any potential during the voltammetric record (Kato Marcus et al., 2007):

$j=j_{\max } /\left(1+\exp \left[-F / R T\left(E-E_{K}\right)\right]\right)$

where $j_{\max }$ is the maximum current density provided at the plateau, $F$ the Faraday constant $\left(96,485 \mathrm{Cb} \mathrm{mol}^{-1} \mathrm{e}^{-}\right), R$ the gas constant $\left(8.3145 \mathrm{~J} \mathrm{~mol}^{-1} \mathrm{~K}\right), T$ the temperature $(300 \mathrm{~K})$, and $E_{K}$ the anode potential $(V)$ at which $j=j_{\max } / 2$. This equation predicts that the maximum current plateau is reached at an overpotential of around $0.2 \mathrm{~V}$. Here, the overpotential required to reach the maximum plateau was significantly larger, which indicated that electron transfer to the electrode was not fast enough to ensure the Nernst equilibrium. Nevertheless, the electron transfer kinetics of the bioanodes formed in the inoculated synthetic medium was considerably more efficient than that of the electrodes formed in inoculated wastewater. In this case, an overpotential of more than $0.7 \mathrm{~V}$ was not sufficient to reach the maximum current. Finally, the voltammetry (R5) confirmed that the bioanodes formed without the activated sludge inoculum did not exhibit significant electroactivity. 
Non-turnover cyclic voltammetries were recorded at day 30 when the acetate was almost fully depleted (Fig. 3). The bioanodes formed in synthetic medium (R1) exhibited a single well-defined redox system with potential midpoint around $-0.4 \mathrm{~V}$ vs. SCE, which was also observed, in a slightly less obvious form, with the bioanodes formed in inoculated wastewater (R3). A similar current peak around $-0.4 \mathrm{~V}$ vs. SCE has already been reported with bioanodes formed from pure cultures of Geobacter sulfurreducens and has been attributed to the redox reaction of multiheme cytochrome OmcZ $(-0.42 \mathrm{~V})$ or OmcB $(-0.39 \mathrm{~V})$ (Zhu et al., 2012). It may consequently be expected that the microbial communities forming these bioanodes contained Geobacter related species. Consistently with the catalytic $\mathrm{CV}$, the bioanodes formed without the activated sludge inoculum (R5) did not possess an efficient redox system, below $0.2 \mathrm{~V}$ vs. SCE.
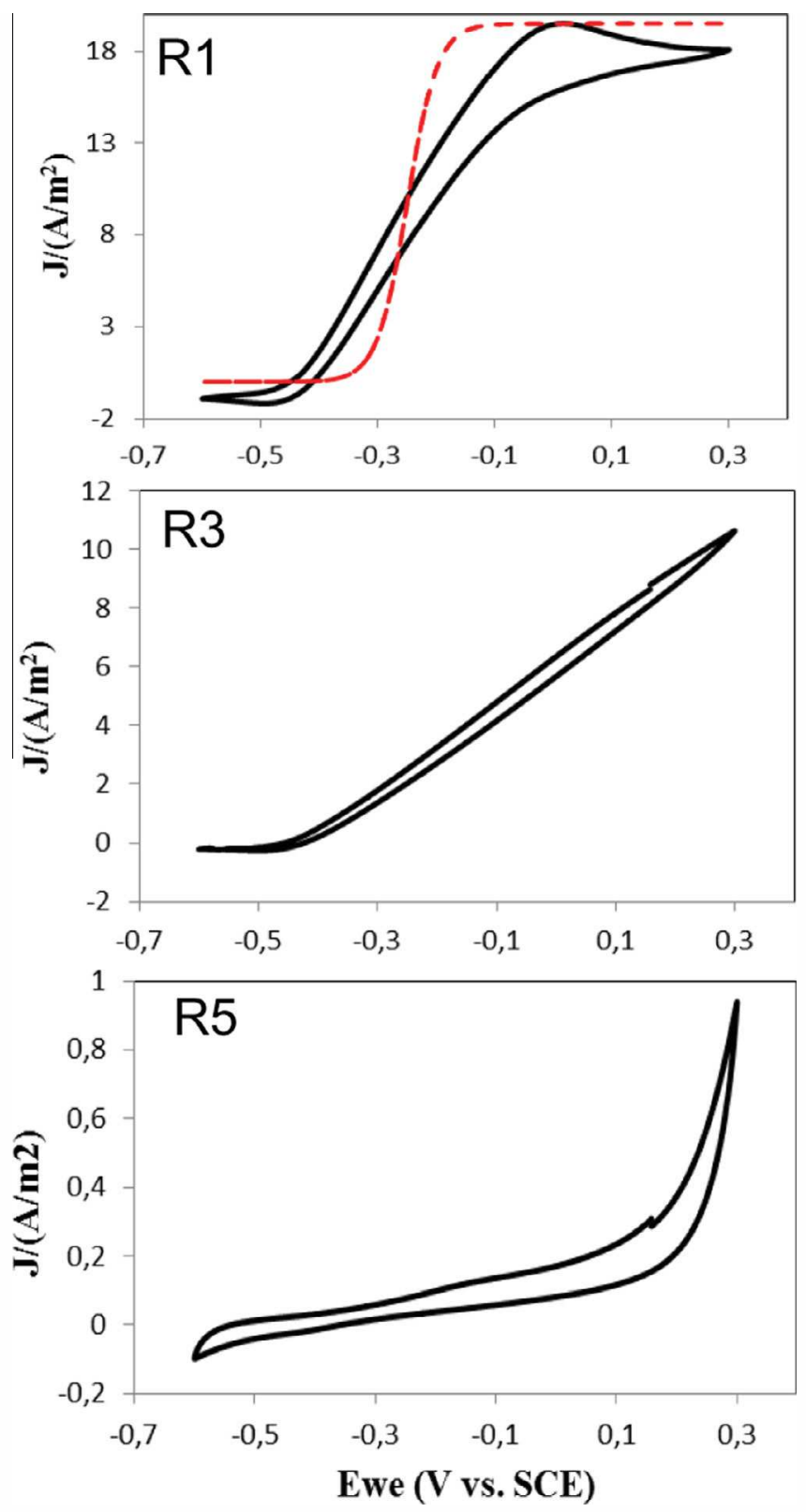

Fig. 2. Catalytic voltammetries recorded on day 37. (R1): biofilm formed in synthetic medium with activated sludge inoculum; (R3): biofilm formed in wastewater with activated sludge inoculum; (R5): biofilm formed in wastewater without the activated sludge inoculum. The dotted sigmoid curve in the R1 CV represents the Nernst-Michaelis equation.
The current peaks of non-turnover voltammetry give an assessment of the redox compounds that can be electrochemically accessed by the electrode. The charge calculated by integrating the current under the anodic peak is proportional to the quantity of redox compounds that can release electrons to the electrode. Here, the charge under the peak was difficult to calculate because of the presence of a remaining catalytic current (exposure of the bioanodes to a stringent substrate deficiency was avoided, as it could have harmed them). Nevertheless, the charge was assessed by integrating the current peak after extracting the catalytic current, assumed to be the current at $0.15 \mathrm{~V}$ vs. SCE. The charge densities were 0.33 and $0.06 \mathrm{C} / \mathrm{m}^{2}$ for the bioanodes formed in synthetic medium (R1) and wastewater (R3), respectively. Although approximate, this calculation clearly points out the lower electron transfer capability of the bioanodes formed in wastewater with respect to those formed in synthetic medium. Actually, the
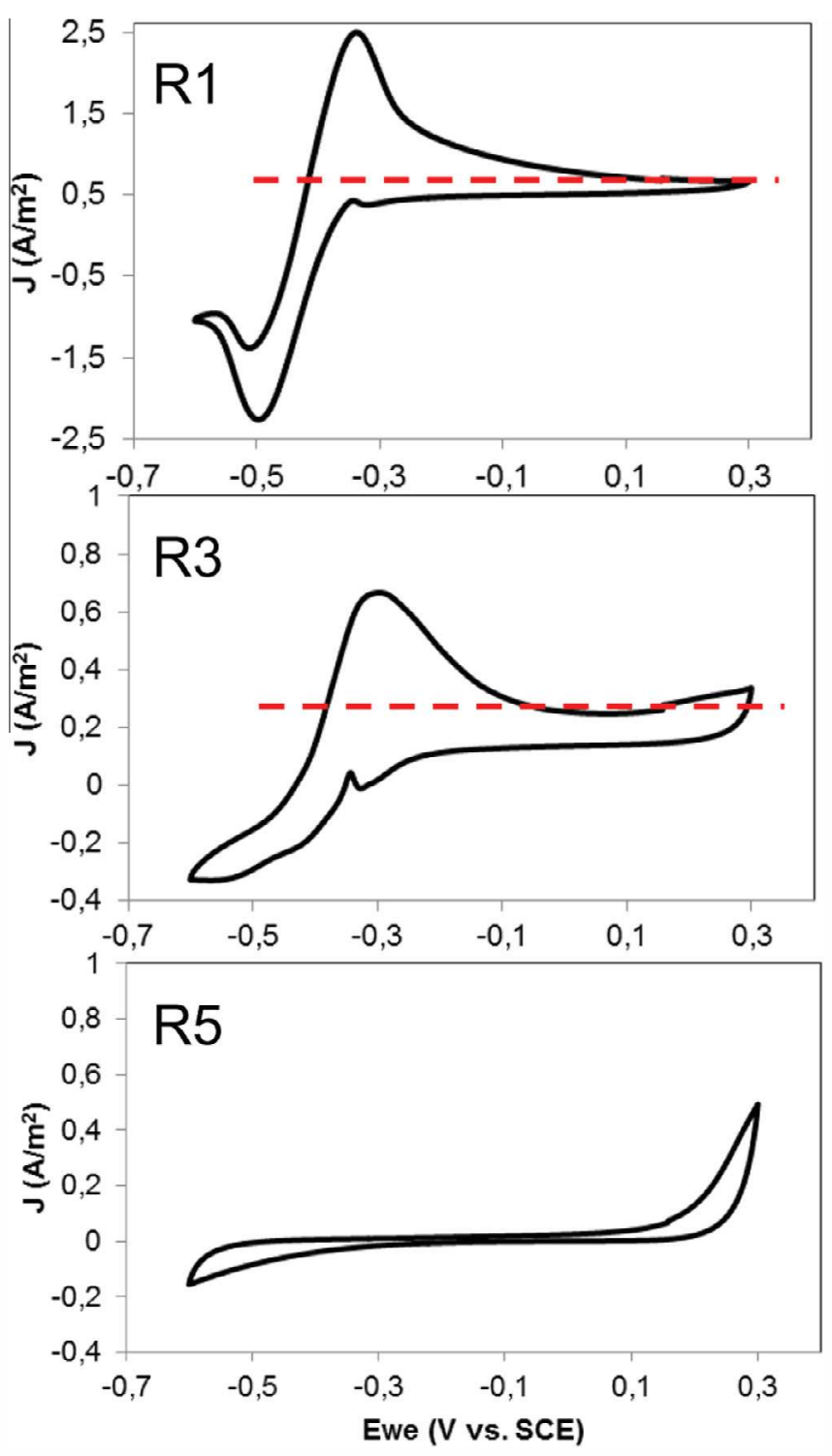

Fig. 3. Non-turnover cyclic voltammetry recorded after almost complete depletion of acetate (day 30). (R1): biofilm formed in synthetic medium with activated sludge inoculum; (R3): biofilm formed in wastewater with activated sludge inoculum; (R5): biofilm formed in wastewater without the activated sludge inoculum. The dotted lines in the R1 and R3 CVs represent the estimation of the catalytic current that was extracted to integrate the current under the anodic peaks. 
biofilms formed in wastewater were thicker but they offered the electrode a smaller amount of accessible redox compounds.

The value of $0.33 \mathrm{C} / \mathrm{m}^{2}$ found in the synthetic medium was close to the values of 0.5 and up to $1 \mathrm{C} / \mathrm{m}^{2}$ reported in the literature for well-developed G. sulfurreducens (Schrott et al., 2011). The secondary bioanodes designed here in synthetic medium confirmed their excellent electrochemical characteristics, which were not far from those of bioanodes composed of $G$. sulfurreducens only. The bioanodes formed in wastewater presented better biofilm coverage and thicker biofilm (see Section 3.2) but they produced lower current density and exhibited less efficient electron transfer kinetics (see catalytic voltammetry). The lower electrochemical performance was explained by the smaller amount of accessible redox compounds here. The lower accessible charge in a thicker biofilm also corroborated the possible significant presence of non-electroactive strains in the biofilm microbial community.

\subsection{Analysis of the microbial communities}

The microbial communities of primary and secondary bioanodes and primary and secondary media were analyzed by $16 \mathrm{~S}$ rRNA pyrosequencing. The activated sludge used as inoculum and the wastewater used as the medium were also analyzed for comparison. The microbial community distribution is given in Table 2 in percentage of total sequences at the phylum level.

At the pylum level, the activated sludge inoculum was composed of $44 \%$ of Proteobacteria, 38\% of Bacteroidetes, and 18\% of others. Wastewater microbial composition was also dominated by Proteobacteria (60\%). The Proteobacteria phylum included a majority of Betaproteobacteria (28\%) for the activated sludge, while it was divided between Beta- Gamma- and Epsilonproteobacteria for wastewater. These results are consistent with those of other studies that have reported Proteobacteria and Bacteroidetes as the 2 groups most frequently retrieved in wastewater treatment plants (Wagner et al., 2002).

The microbial communities of the primary and secondary bioanodes were also dominated by the Proteobacteria. Inside this phylum, Deltaproteobacteria emerged as the dominant class for the bioanodes formed in R1 and R3. Comparison between primary and secondary biofilms indicated an enrichment from 36\% to $60 \%$ of Deltaproteobacteria in R1 and from 33\% to $41 \%$ in R3. In contrast, Deltaproteobacteria represented respectively only $13 \%$ and $6 \%$ for primary and secondary bioanodes formed in R5 that did not provide significant currents, and did not show improvement from primary to secondary.

Among the Deltaproteobacteria class, a majority of Desulfuromonadales was identified, which are known to have electroactive representatives. From the primary to the secondary bioanodes, their percentage of total sequences increased from 33 to $59 \%$ in $\mathrm{R} 1$ and, from $25 \%$ to $36 \%$ in $\mathrm{R} 3$ while remaining at $1 \%$ and 3\% in R5 (Fig. 4). Going deeper in the taxonomic classification showed that all the Desulfuromonadales belonged to the family of Geobacteraceae. The strong presence of Geobacteraceae in the most efficient bioanodes (R1), their quasi-absence in the poorly performing bioanodes (R5) and the clear enrichment from primary to secondary bioanodes strongly suggested that the bioanode electroactivity was related to the selection of Geobacteraceae.

Plotting the current density provided by the different bioanodes versus the percentage of Geobacteraceae demonstrated a fair correlation between the bioanode performance and the Geobacteraceae selection (Fig. 5). Enrichment in bacteria belonging to the family Geobacteraceae was the essential driving force of the optimization procedure. High current densities have often been reported to be associated with the dominance of Geobacter-related species (Kiely et al., 2011; Zhu et al., 2013). However, this observation was confirmed for the first time here by a correlation supported by several values of the current density being a function of Geobacteraceae percentage.

A maximum-likelihood phylogenetic tree that included several sequences of type species from the order Desulfuromonadales, together with sequences from uncultured bacteria closely related to our OTUs was reconstructed and is presented in the Supplementary Material (Fig. S2).

The bioanodes from R1 and R3 did not develop the same species among Geobacteraceae. In the synthetic medium (R1), OTUs 52989 and 14374 made up more than $50 \%$ of the Desulfuromonadales identified at the primary bioanode and up to $83 \%$ at the secondary. In wastewater (R3), OTU 1660 was dominant, representing more than $70 \%$ of the Desulfuromonadales in both primary and secondary biofilms.

OTU 52989 corresponds to G. sulfurreducens, while OTUs 14374 and 1660 remain as uncultured bacteria in the database. OTU 14374 is close to the branch to which Geobacter chapellei, Geobacter psychrophilus and Pelobacter propionicus belong, whereas OTU 1660 belongs to the same branch as G. metallireducens, G. grbiciae and G. hydrogenophilus.

The medium used to form the bioanodes had a great impact on the microbial species that composed the biofilms: the synthetic medium favoured the growth of G. sulfurreducens and OTU 14714 (related to an uncultured Geobacter sp.), while growth of another Geobacter sp. (OTU 1660) was favoured in wastewater.

Those OTUs make up less than $0.1 \%$ in the activated sludge inoculum and less than $1 \%$ in wastewater. Only a strong selective pressure can explain their dominance in the bioanodes. The microbial enrichment was also demonstrated by the diversity indexes, calculated for each bioanode and each corresponding medium (Supplementary Material - Table S1). Chao1, estimating total species richness, was higher for each primary bioanode than for the secondary bioanode. It was inversely correlated to the anodic performance. Shannon and Simpson indexes also showed that diversity decreased at the secondary bioanodes, confirming the enrichment in electroactive bacteria. Diversity was systematically

Table 2

Microbial community distributions in percentage of total sequences at the phylum level for primary bioanodes (PB), secondary bioanodes (SB) in reactors R1, R3 and R5, Activated Sludge (AS) used as inoculum and wastewater (WW). Distribution at the class level is given for the Proteobacteria group. The red circles highlight the main classes as determined by pyrosequencing of $16 S$ rRNA.

\begin{tabular}{|c|c|c|c|c|c|c|c|c|c|}
\hline \multirow{2}{*}{$\begin{array}{l}\text { Phylum } \\
\text { Class }\end{array}$} & \multicolumn{6}{|c|}{ Proteobacteria \% } & \multirow[t]{2}{*}{ Bacteroidetes \% } & \multirow[t]{2}{*}{ Firmicutes \% } & \multirow[t]{2}{*}{ Others } \\
\hline & $\alpha$ & $\beta$ & $\gamma$ & $\delta$ & $\varepsilon$ & Total & & & \\
\hline AS - inoc & 5 & 28 & 5 & 3 & 3 & 44 & 38 & 3 & 15 \\
\hline WW - effluent & 2 & 18 & 18 & 3 & 19 & 60 & 23 & 9 & 8 \\
\hline R1-PB & 1 & 3 & 12 & 36 & 18 & 70 & 20 & 3 & 7 \\
\hline R3-PB & 0 & 3 & 0 & 33 & 21 & 57 & 26 & 5 & 12 \\
\hline R5-PB & 2 & 20 & 5 & 13 & 3 & 43 & 32 & 12 & 13 \\
\hline R1-SB & 0 & 1 & 1 & 60 & 0 & 62 & 24 & 4 & 10 \\
\hline R3-SB & 1 & 2 & 1 & 41 & 4 & 49 & 33 & 5 & 13 \\
\hline R5-SB & 3 & 14 & 2 & 6 & 43 & 68 & 17 & 5 & 10 \\
\hline
\end{tabular}




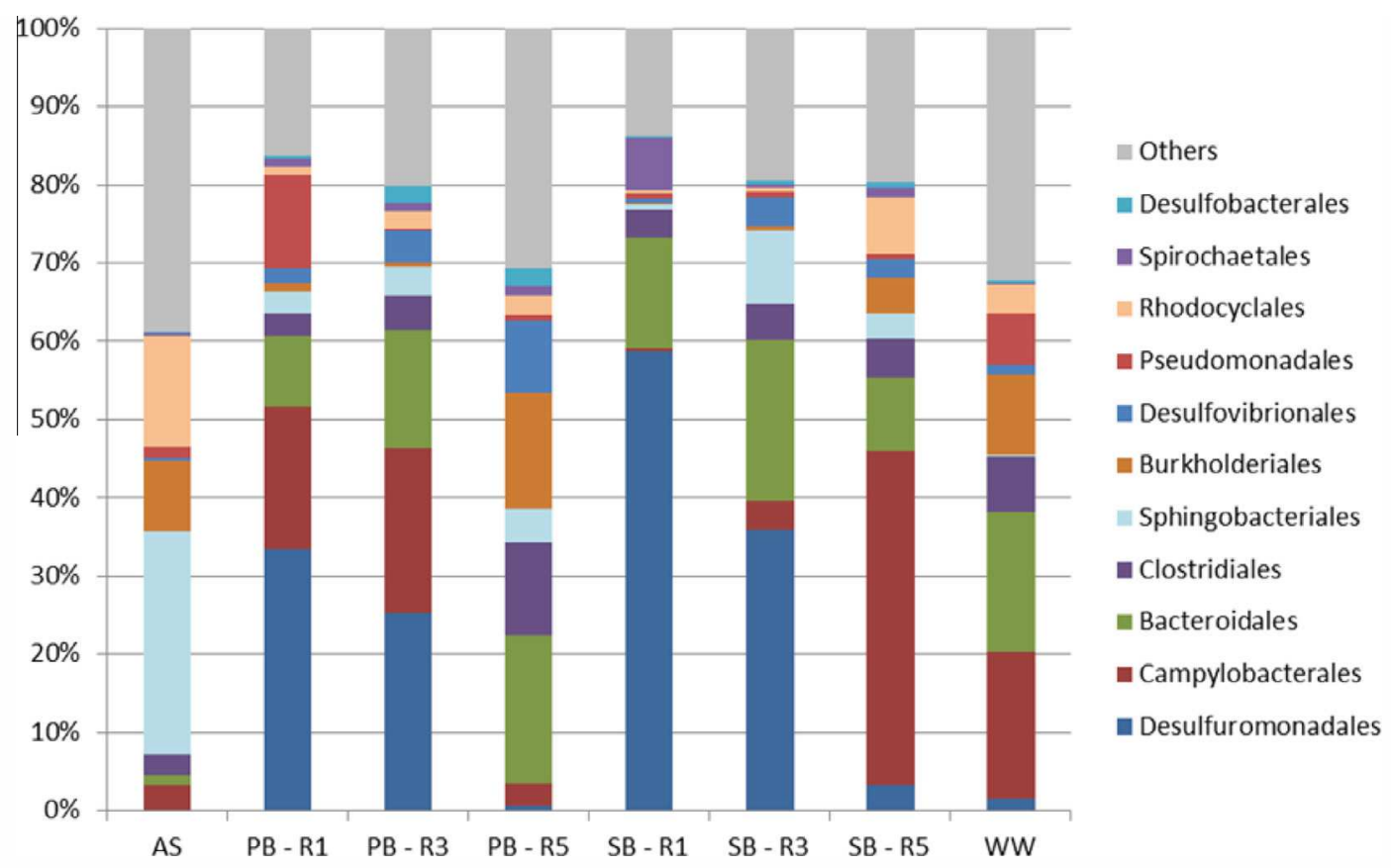

Fig. 4. Major bacterial orders identified for primary bioanodes (PB) and secondary bioanodes (SB) of the reactors R1, R3 and R5. Activated sludge (AS) and wastewater (WW) were also analyzed.

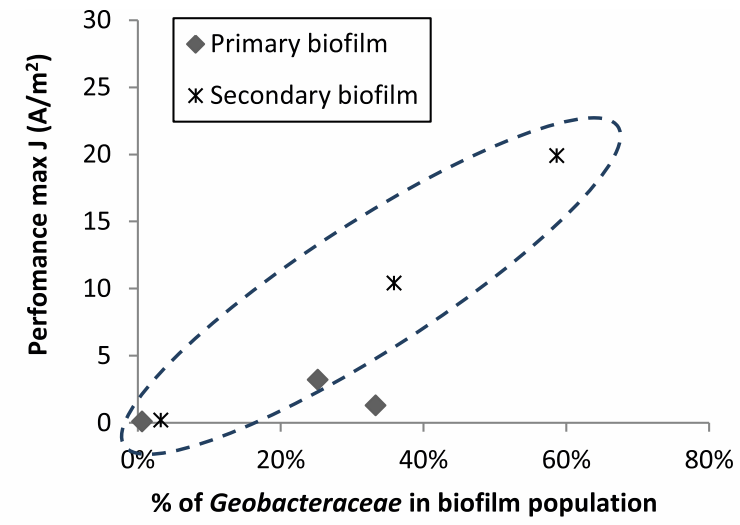

Fig. 5. Correlation between the maximal current densities and the percentage of Geobacteraceae in bioanode microbial communities.

lower in the biofilm than in the medium, except for R5, which did not show any enrichment in Deltaproteobacteria and did not provide significant current.

Up to the family level, the formation of bioanodes in synthetic medium or in wastewater obeyed a fairly similar process: the electrochemical pressure selected for Geobacteraceae and the electrochemical performance of the bioanodes were roughly related to the percentage of Geobacteraceae. The synthetic medium (SB1Chao1 $=4750$ ) resulted in a more stringent selection than the wastewater medium $(S B 3-C h a o 1=5586$ ) and resulted in biofilms mainly wrapped around the fibres of the electrode on which electroactive bacteria grew in priority. Wastewater allowed the development of a larger diversity of microbial species, probably including a high number of non-electroactive bacteria. This resulted in the formation of compact biofilms that were able to fill the inter-fibre spaces. These bioanodes produced lower current density, probably because of less efficient mass transfers and electron transfers, as demonstrated by the cyclic voltammetry, which indicated less efficient electron transfer kinetics due to a smaller amount of accessible redox compounds. Surprisingly, at the species level, the bioanodes formed in synthetic medium or in wastewater revealed clearly different features. Among the Geobacteraceae, the synthetic medium favoured the growth of G. sulfurreducens and OTU 14714 closely related to an uncultured Geobacter sp., while wastewater promoted the development of another Geobacter sp. (OTU 1660). Actually the smaller efficiencies of these bioanodes may also be related to the different Geobacter species that were involved.

\subsection{Scalable strategy applied to food wastes}

Finally, the interest of the strategy was checked by replacing the acetate substrate by food waste. Two reactors (R7 and 8) were run in parallel (duplicates) in the conditions described above, with wastewater inoculated by activated sludge and following the 3 step procedure (Fig. 6A). A food waste dose having a volume of $10 \mathrm{~mL}$ was chosen to obtain a COD close to that of $10 \mathrm{mM}$ of acetate $\left(0.65 \mathrm{gO}_{2} / \mathrm{L}\right)$. The addition of $10 \mathrm{~mL}$ of food waste $\left(43 \mathrm{gO}_{2} / \mathrm{L}\right)$ in the $600 \mathrm{~mL}$ reactors led to a COD of $0.7 \mathrm{gO}_{2} / \mathrm{L}$.

The general trend was similar to the previous results obtained with acetate (Fig. 1) and the improvement factor from the primary to the secondary bioanodes was considerable. The current density provided by the primary bioanodes did not exceed $0.2 \mathrm{~A} / \mathrm{m}^{2}$ after 3 batches, while the secondary bioanodes reached 8.1 (R7) and 5.9 (R8) $\mathrm{A} / \mathrm{m}^{2}$. This means an improvement by a factor of 35 on average. Here, the primary/secondary procedure proved to be extremely efficient. Actually, a premature and wrong conclusion encouraged by looking at the primary bioanodes only might be that food wastes were not appropriate to feed a microbial anode when wastewater was used as the dilution medium. In contrast, the secondary bioanodes demonstrated the high potential of food wastes combined with wastewater dilution.

$\mathrm{pH}$ monitoring revealed that $\mathrm{pH}$ decreased by 0.5 unit for each new batch of wastewater supplemented with $10 \mathrm{~mL}$ of food wastes (Fig. 6B). Then, pH went back to its initial value as the organic acids contained in the waste were consumed. This auto-regulation of the $\mathrm{pH}$ was observed with food waste pulses of $0.7 \mathrm{gO}_{2} / \mathrm{L}$ but was compromised when the concentration of the pulse was doubled (data 

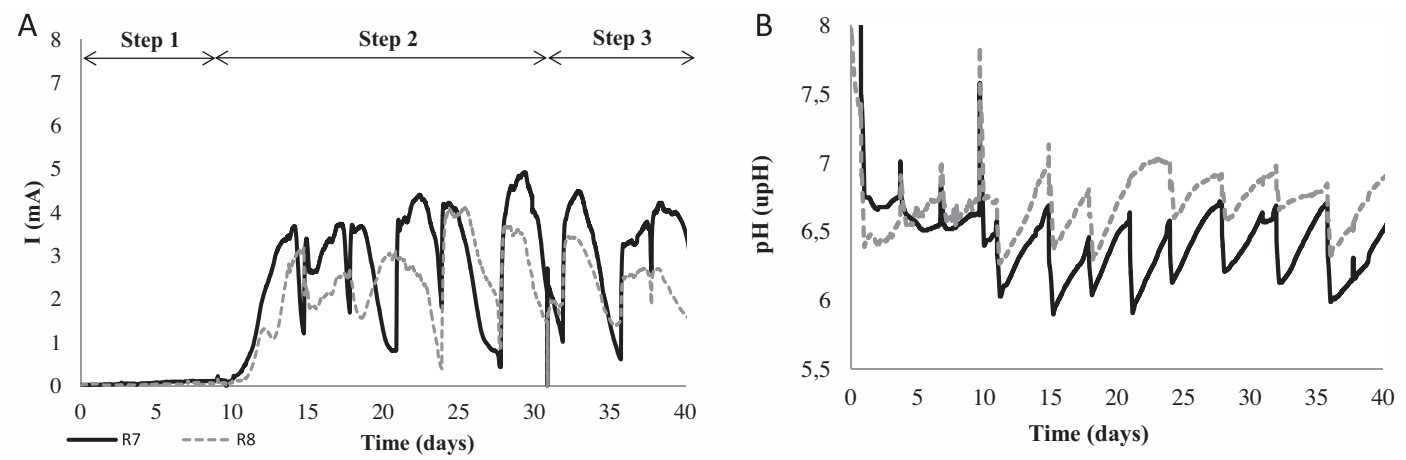

Fig. 6. Current intensities recorded on carbon cloth electrode polarized at $0.15 \mathrm{~V}$ vs. SCE (A) and pH values (B) in R7 and R8 (duplicates) fed with food waste in wastewater as dilution medium and inoculated with activated sludge.

not shown). The $\mathrm{pH}$ decreased to 5.7 with a $20 \mathrm{~mL}$ dose of food waste. Organic loading rate (OLR) is an important parameter for optimizing the performance. Goud et al. (2011) have shown that high OLR operation caused a large drop in $\mathrm{pH}$ (to 5.5-5.6), which suppressed the power generation of their MFC. They suggested enhancing the buffering capacity to improve power yields at higher loading rates. In our system, the buffering capacity of wastewaters remained low and dilution was required to avoid inhibition due to $\mathrm{pH}$ decrease. The low cost of wastewater used as dilution medium comes at the price of strict OLR control.

From a practical point of view, wastewater used as dilution medium was shown to be a promising solution for designing scalable bioanodes. With $10 \mathrm{mM}$ acetate as substrate, wastewater ensured $50 \%$ of the current density obtained in the optimal synthetic medium. In this last section, replacing acetate by food wastes led to $33 \%$ of the current density that was obtained in the ideal case using acetate in synthetic medium. This result is really quite encouraging, given the large gap that exists in the literature between the performance levels reported in synthetic media amended with acetate and in real wastes (see Section 1).

If the objective was to treat large quantities of concentrated wastes, it would not be reasonable to contemplate large-sized electro-microbial technologies requiring huge amounts of phosphate salts and the addition of costly micro-nutriments and vitamins. Here, using low-cost (or even cost-free) wastewater proved to be a fair alternative solution at the cost of an acceptable performance loss and the necessity for careful OLR control to master pH evolution. The causes of the lower performance in wastewater have been identified as the biofilm structure and microbial composition and work should now be pursued on this basis to improve the bioanode electrochemical properties.

\section{Conclusion}

Bioanodes can be designed by replacing the costly synthetic media commonly used in small-sized reactors by wastewater that can be implemented at very large scale. Obviously, the synthetic medium ensured higher current densities but wastewater succeeded in producing $50 \%$ of the performance. In both cases, the electrocatalytic efficiency was correlated with the selection of microbial species of the Geobacteraceae family.

The primary/secondary procedure allowed bioanodes able to treat food wastes to be successfully designed using wastewater as the dilution medium. This strategy offers a way to scale-up bioanodes to large size at low cost in order to treat concentrated wastes.

\section{Acknowledgements}

This work was part of the "BIORARE" project (ANR-10-BTBR02), partly funded by the French Agence Nationale de la
Recherche (ANR) and the Comité des Investissements d'Avenir. The authors thank Marie-Line de Solan (LGC) for her help with the SEM images and Luc Etcheverry (LGC) for helping with activated sludge and wastewater sampling. We also kindly thank Ms. Susan Becker for her help in correcting the English version of the manuscript.

\section{Appendix A. Supplementary data}

Supplementary data associated with this article can be found, in the online version, at http://dx.doi.org/10.1016/j.biortech.2015.02. 097.

\section{References}

Baudler, A., Riedl, S., Schröder, U., 2014. Long-term performance of primary and secondary electroactive biofilms using layered corrugated carbon electrodes. Bioenergy Biofuels 2, 30.

Caporaso, J.G., Bittinger, K., Bushman, F.D., DeSantis, T.Z., Andersen, G.L., Knight, R. 2010a. PyNAST: a flexible tool for aligning sequences to a template alignment. Bioinformatics 26, 266-267.

Caporaso, J.G., Kuczynski, J., Stombaugh, J., Bittinger, K., Bushman, F.D., Costello, E.K., Fierer, N., Peña, A.G., Goodrich, J.K., Gordon, J.I., Huttley, G.A., Kelley, S.T., Knights, D., Koenig, J.E., Ley, R.E., Lozupone, C.A., McDonald, D., Muegge, B.D., Pirrung, M., Reeder, J., Sevinsky, J.R., Turnbaugh, P.J., Walters, W.A., Widmann, J., Yatsunenko, T., Zaneveld, J., Knight, R., 2010b. QIIME allows analysis of highthroughput community sequencing data. Nat. Methods 7, 335-336.

Cercado-Quezada, B., Delia, M.-L., Bergel, A., 2010. Testing various food-industry wastes for electricity production in microbial fuel cell. Bioresour. Technol. 101, $2748-2754$.

Choi, J., Chang, H.N., Han, J.-I., 2011. Performance of microbial fuel cell with volatile fatty acids from food wastes. Biotechnol. Lett. 33, 705-714.

Cole, J.R., Wang, Q., Cardenas, E., Fish, J., Chai, B., Farris, R.J., Kulam-Syed-Mohideen, A.S., McGarrell, D.M., Marsh, T., Garrity, G.M., Tiedje, J.M., 2009. The Ribosomal Database Project: improved alignments and new tools for rRNA analysis. Nucleic Acids Res. 37, D141-D145.

Criscuolo, A., Gribaldo, S., 2010. BMGE (Block Mapping and Gathering with Entropy): a new software for selection of phylogenetic informative regions from multiple sequence alignments. BMC Evol. Biol. 10, 210.

Edgar, R.C., 2010. Search and clustering orders of magnitude faster than BLAST. Bioinformatics 26, 2460-2461.

Feng, Y., Wang, X., Logan, B.E., Lee, H., 2008. Brewery wastewater treatment using air-cathode microbial fuel cells. Appl. Microbiol. Biotechnol. 78, 873-880.

Foladori, P., Bruni, L., Tamburini, S., Ziglio, G., 2010. Direct quantification of bacterial biomass in influent, effluent and activated sludge of wastewater treatment plants by using flow cytometry. Water Res. 44, 3807-3818.

Goud, R.K., Babu, P.S., Mohan, S.V., 2011. Canteen based composite food waste as potential anodic fuel for bioelectricity generation in single chambered microbial fuel cell (MFC): bio-electrochemical evaluation under increasing substrate loading condition. Int. J. Hydrog. Energy 36, 6210-6218.

Guindon, S., Gascuel, O., 2003. A simple, fast, and accurate algorithm to estimate large phylogenies by maximum likelihood. Syst. Biol. 52, 696-704.

Haas, B.J., Gevers, D., Earl, A.M., Feldgarden, M., Ward, D.V., Giannoukos, G., Ciulla, D., Tabbaa, D., Highlander, S.K., Sodergren, E., Methé, B., DeSantis, T.Z., Petrosino, J.F., Knight, R., Birren, B.W., 2011. Chimeric 16S rRNA sequence formation and detection in Sanger and 454-pyrosequenced PCR amplicons. Genome Res. 21, 494-504.

Kato Marcus, A., Torres, C.I., Rittmann, B.E., 2007. Conduction-based modeling of the biofilm anode of a microbial fuel cell. Biotechnol. Bioeng. 98, 1171-1182. 
Ketep, S.F., Bergel, A., Calmet, A., Erable, B., 2014. Stainless steel foam increases the current produced by microbial bioanodes in bioelectrochemical systems. Energy Environ. Sci. 7, 1633.

Ketep, S.F., Fourest, E., Bergel, A., 2013. Experimental and theoretical characterization of microbial bioanodes formed in pulp and paper mill effluent in electrochemically controlled conditions. Bioresour. Technol. 149, $117-125$.

Kiely, P.D., Regan, J.M., Logan, B.E., 2011. The electric picnic: synergistic requirements for exoelectrogenic microbial communities. Curr. Opin. Biotechnol. 22, 378-385.

Liu, Y, Harnisch, F., Fricke, K., Sietmann, R., Schröder, U., 2008. Improvement of the anodic bioelectrocatalytic activity of mixed culture biofilms by a simple consecutive electrochemical selection procedure. Biosens. Bioelectron. 24, 1006-1011.

Li, X.M., Cheng, K.Y., Selvam, A., Wong, J.W.C., 2013. Bioelectricity production from acidic food waste leachate using microbial fuel cells: effect of microbial inocula. Process Biochem. 48, 283-288.

Ludwig, W., Strunk, O., Westram, R., Richter, L., Meier, H., Yadhukumar Buchner, A., Lai, T., Steppi, S., Jobb, G., Förster, W., Brettske, I., Gerber, S., Ginhart, A.W., Gross, O., Grumann, S., Hermann, S., Jost, R., König, A., Liss, T., Lüßmann, R., May, M., Nonhoff, B., Reichel, B., Strehlow, R., Stamatakis, A., Stuckmann, N., Vilbig, A. Lenke, M., Ludwig, T., Bode, A., Schleifer, K.-H., 2004. ARB: a software environment for sequence data. Nucleic Acids Res. 32, 1363-1371.

Miksch, K., Cema, G., Corvini, P.F.-X., Felis, E., Sochacki, A., Surmacz-Górska, J., Wiszniowski, J., Zabczynski, S., 2013. R\&D priorities in the field of sustainable remediation and purification of agro-industrial and municipal wastewater. New Biotechnol.

Oh, S., Logan, B.E., 2005. Hydrogen and electricity production from a food processing wastewater using fermentation and microbial fuel cell technologies. Water Res. 39, 4673-4682.

Pant, D., Arslan, D., Van Bogaert, G., Gallego, Y.A., De Wever, H., Diels, L., Vanbroekhoven, K., 2013. Integrated conversion of food waste diluted with sewage into volatile fatty acids through fermentation and electricity through a fuel cell. Environ. Technol. 34, 1935-1945.

Pant, D. Van Bogaert, G. Diels, L., Vanbroekhoven, K., 2010. A review of the substrates used in microbial fuel cells (MFCs) for sustainable energy production. Bioresour. Technol. 101, 1533-1543.
Patil, S.A., Surakasi, V.P., Koul, S., Ijmulwar, S., Vivek, A., Shouche, Y.S., Kapadnis, B.P., 2009. Electricity generation using chocolate industry wastewater and its treatment in activated sludge based microbial fuel cell and analysis of developed microbial community in the anode chamber. Bioresour. Technol. 100, 5132-5139.

Quast, C., Pruesse, E., Yilmaz, P., Gerken, J., Schweer, T., Yarza, P., Peplies, J., Glockner, F.O., 2013. The SILVA ribosomal RNA gene database project: improved data processing and web-based tools. Nucleic Acids Res. 41, D590-D596.

Rimboud, M., Pocaznoi, D., Erable, B., Bergel, A., 2014. Electroanalysis of microbial anodes for bioelectrochemical systems: basics, progress and perspectives. Phys. Chem. Chem. Phys.

Rodrigo, M.A., Cañizares, P., Lobato, J., Paz, R., Sáez, C., Linares, J.J., 2007. Production of electricity from the treatment of urban waste water using a microbial fuel cell. J. Power Sources, CONAPPICE 2006 Selected Papers Presented at the 2nd National Congress on Fuel Cells (CONAPPICE 2006), Madrid, Spain, 18-20 October 2006, vol. 169, pp. 198-204.

Schrott, G.D., Bonanni, P.S., Robuschi, L., Esteve-Nuñez, A., Busalmen, J.P., 2011. Electrochemical insight into the mechanism of electron transport in biofilms of Geobacter sulfurreducens. Electrochimica Acta. Selected Papers from the 61st ISE Meeting, Nice, France, 2010 56, 10791-10795.

Tenca, A. Cusick, R.D.,Schievano, A., Oberti, R., Logan, B.E., 2013. Evaluation of low cost cathode materials for treatment of industrial and food processing wastewater using microbial electrolysis cells. Int. J. Hydrog. Energy 38, 1859-1865.

Torres, C.I., Kato Marcus, A., Rittmann, B.E., 2008. Proton transport inside the biofilm limits electrical current generation by anode-respiring bacteria. Biotechnol. Bioeng. 100, 872-881.

Wagner, M., Loy, A., Nogueira, R., Purkhold, U., Lee, N., Daims, H., 2002. Microbial community composition and function in wastewater treatment plants. Antonie Van Leeuwenhoek 81, 665-680.

Wang, H., Ren, Z.J., 2013. A comprehensive review of microbial electrochemical systems as a platform technology. Biotechnol. Adv. 31, 1796-1807.

Zhu, X., Yates, M.D., Hatzell, M.C., Ananda Rao, H., Saikaly, P.E., Logan, B.E., 2013. Microbial Community Composition Is Unaffected by Anode Potential. Environ. Sci. Technol.

Zhu, X., Yates, M.D., Logan, B.E., 2012. Set potential regulation reveals additional oxidation peaks of Geobacter sulfurreducens anodic biofilms. Electrochem. Commun. 22, 116-119. 